\title{
Editorial
}

Nephrology

\section{Vancomycin Trough Levels: Cause or Result of Acute Kidney Injury?}

\author{
William M. Bennett \\ Legacy Good Samaritan Medical Center, Portland, Oreg., USA
}

In the current issue of the American Journal of $\mathrm{Ne}$ phrology, Hammoud et al. [1] present a large retrospective study relating the vancomycin trough level in $500 \mathrm{pa}-$ tients with acute kidney injury (AKI). With the widespread use of vancomycin for various infections including resistant organisms such as methicillin-resistant Staphylococcus aureus, the nephrotoxicity of this compound has been reexamined.

Early in its development vancomycin was manufactured with various impurities that were believed to be the source of the drug's nephrotoxic potential [2]. It has been difficult to produce vancomycin nephrotoxicity in experimental animals over the past years although there seems to be a synergistic nephrotoxic effect when combined with aminoglycoside $[3,6]$. The instance of nephrotoxicity defined differently by various authors has been estimated to be approximately 5\% [4]. The major concern of most infectious disease specialists is to achieve the drug regimen that is necessary to cure the bacterial infection for which the drug was prescribed. Thus, the trough levels as an estimate of drug exposure has become the focus of various guidelines for vancomycin usage.

From a renal standpoint, vancomycin is a very interesting compound. The molecular weight is 1,500 and there are no metabolites of significance. Excretion is virtually entirely renal, and in fact, the ratio of the renal clearance of vancomycin to the clearance of the gold standard glomerular filtration rate (GFR) marker inulin is 0.89 in normal volunteers at steady state with endogenous creatinine as a filtration marker the ratio is 0.79 [5]. Therefore, the vancomycin clearance is a better GFR marker than is the creatinine clearance. Thus the interpretation of trough levels needs to be based on the renal function of the treated patient.

Vancomycin is only prescribed for infected patients. Obviously, the hemodynamic effects of infection inclusive of systemic sepsis make each patient unique in regard to their risk of AKI in the course of vancomycin treatment. The authors tried to adjust for this with various demographic factors. However, the ways of expressing the trough levels without any information about hemodynamics and the nature of the infections other than the site of infection makes the matching regarding AKI and non-AKI patients unclear.

The trough level of any compound is a surrogate for the exposure of the drug in the patient, given that exposure is defined by the area under the concentration curve (AUC) and the trough level is just one point on the AUC. Thus, as renal function falls while other factors remain the same, the trough level of vancomycin will rise. That does not mean that the trough level causes nephrotoxicity but rather is a result of incomplete drug excretion dur-

\section{KARGER}

E-Mail karger@karger.com www.karger.com/ajn (c) 2016 S. Karger AG, Basel

0250-8095/16/0446-0454\$39.50/0
William M. Bennett, MD

Legacy Transplant Services

Legacy Good Samaritan Medical Center

1040 NW 22nd Avenue, Suite 480, Portland, OR 97210 (USA)

E-Mail bennettw@lhs.org 
ing the dosing interval. Thus, it is possible that the actual trough level is a function of the renal clearance of the drug which is, as mentioned above, more sensitive than the creatinine-based clearances or equations. Another way of stating this is that the vancomycin trough level is probably a more sensitive renal function parameter than is serum creatinine. Since the AKI in this cohort was defined by creatinine elevations, it is possible that the 'risk' of high trough levels is simply the result of renal dysfunction and not the cause of it. In this regard, vancomycin would be similar to the aminoglycoside antibiotics gentamicin and tobramycin, where elevated trough levels there are a result of nephrotoxicity and not a cause [7]. For the nephrologists, although not tested in this study, the measurement of serial trough levels would indicate impaired renal excretion before a rise in serum creatinine can be detected and might serve as a preventative signal to re- duce or alter the dosing regimen. Just as we follow trough gentamicin levels to avoid nephrotoxicity, the same strategy probably would work for vancomycin dosing. It appears that vancomycin nephrotoxicity probably does occur due to the transport of some filtered or secreted vancomycin into the renal tubular cell although vancomycin alone is an unusual cause of AKI. However, according to the authors, AKI is probably more common in the setting of sepsis. For further clarification of ideal vancomycin dosage, it will be necessary to study the complete pharmacokinetics and prospectively correlate them with renal biomarkers including the trough vancomycin level.

\section{Disclosure Statement}

The author has no conflicts of interest to report.

\section{References}

1 Hammoud K, Brimacombe M, Yu A, Goodloe N, Haidar W, El Atrouni W: Vancomycin trough and acute kidney injury: a large retrospective, cohort study. Am J Nephrol 2016; 44:456-461.

2 Elting LS, Rubenstein EB, Kurtin D, Rolston KV, Fangtang J, Martin CG, Raad II, Whimbey EE, Manzullo E, Bodey GP: Mississippi mud in the 1990s: risks and outcomes of vancomycin-associated toxicity in general oncology practice. Cancer 1998;83:25972607.
3 Goetz MB, Sayers J: Nephrotoxicity of vancomycin and aminoglycoside therapy separately and in combination. J Antimicrob Chemother 1993;32:325-334.

4 Decker BS, Molitoris BA: Aminoglycosides and vancomycin; in DeBroe ME, Porter GA, Bennett WM, Deray G (eds): Clinical Nephrotoxins, 2008, pp 267-292.

5 Golper TA, Noonan HM, Elzinga L, Gilbert D, Brummett R, Anderson JL, Bennett WM: Vancomycin pharmacokinetics, renal handling, and nonrenal clearances in normal hu- man subjects. Clin Pharmacol Ther 1988;43: 565-570.

6 Munar MY, Elzinga L, Brummett R, Golper TA, Bennett WM: The effect of tobramycin on the renal handling of vancomycin. J Clin Pharmacol 1991;31:618-623.

7 Bennett WM, Plamp CE, Gilbert DN, Parker RA, Porter GA: The influence of dosage regimen on experimental gentamicin nephrotoxicity: dissociation of peak serum levels from renal failure. J Infect Dis 1979;140:576580 . 